the minister, who, in making this decision, said that LURE doesn't serve a purpose," says Robert Comès, LURE's director. "If it doesn't serve a purpose, there's no reason to have it in use."

More than 300 scientists at LURE met last Monday and voted unanimously — with two abstentions - to leave the machines, which were shut down for August, turned off. Repeating their conviction that Soleil is essential for the future of French science, they agreed to refuse to collaborate in the Franco-British project, and demanded that Allègre reverse his decision.

However, Allègre, who has made European collaboration a cornerstone of his policy, shows no sign of relenting. According to Vincent Courtillot, director of research for the ministry, the government has been trying to trim costs on 'big science' facilities in order to inject more money into research at public laboratories.

"There is no doubt that synchrotron radiation is an important and necessary technique," says Courtillot. "The one thing we have been questioning is whether [Soleil] is really necessary, and whether we are prepared to give a large amount of money to it."

Courtillot admits that Diamond will fulfil only about one-third of French researchers' needs, but adds that the government is already negotiating to rent beamlines on BESSY II in Germany, SLS in Switzerland and Elettra in Italy.

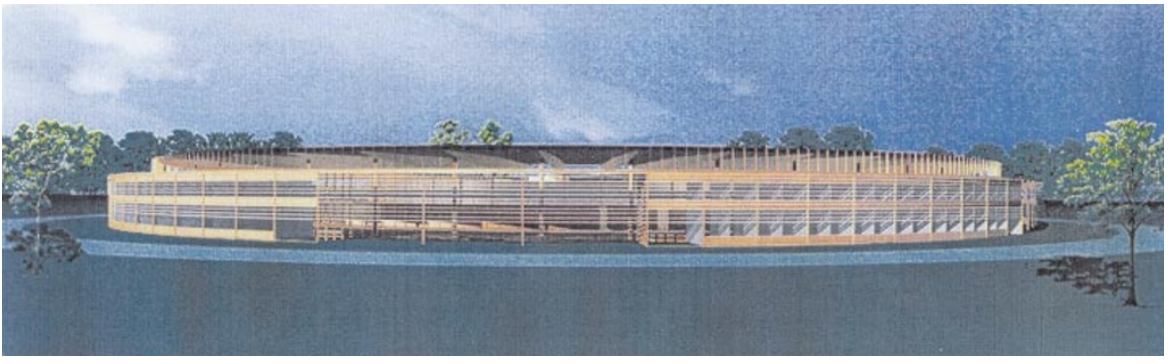

Eclipsed: plans for the Soleil synchrotron facility have been dropped by the French government.

"This should give us two-thirds of Soleil," Courtillot says. He adds that the government plans to join with Britain, France, Germany and Italy in coordinating the development and operation of large facilities, among them synchrotron radiation and neutron sources. This is expected to take up to four years to set up.

Several experts, however, have challenged the ministry's strategy, arguing that it could end up costing more than Soleil, while meeting a substantially smaller fraction of French research needs than Courtillot estimates. For example, researchers say that Diamond will meet one-quarter of their needs, not one-third.

Many question why Soleil is being abandoned for a European project if that project doesn't offer substantially greater benefits. "We have to look at what everything is going to cost, and what the advantages and disadvantages are," says one expert close to the project. "The debate has been very passionate, but there has been no rational discussion.”

Soleil, projected to cost FF1 billion, was to have received FF675 million in regional aid. Scientists point out that the remainder is almost exactly what the government is pledging towards Diamond, and that this does not take into account the cost of renting future beamlines, the additional upkeep of LURE, or travel budgets.

Scientists have demanded that Allègre reveal the details behind his decision, and particularly that he publish a report he commissioned that was favourable to the British plan.

"It seems very curious that the minister made [this] decision without having any interactions with the scientists involved," says one expert.

The protest is likely to continue for a couple of weeks. About 400 scientists work at LURE, and 1,800 visit each year to use its facilities.

Heather McCabe

\title{
Obuchi vows to push university reforms in Japan
}

Tokyo

A plan by the Japanese government to transform the country's 99 national universities into semi-autonomous 'agencies' moved a step closer to reality last week when Keizo Obuchi, the prime minister, promised to enforce the reform if he is re-elected head of the ruling Liberal Democratic Party (LDP).

Obuchi stressed the importance of restructuring the universities in a statement on education policy issued as part of his reelection campaign. The plans are part of a broader effort to increase administrative efficiency by turning government-run organizations into semi-autonomous bodies (see Nature 389, 897; 1997).

Koichi Kato, Obuchi's main opponent in the election and a supporter of Japanese lifescience research, also backs the agency plan as a step towards privatizing the universities. Kato has been critical of the current university system, particularly the restrictions of civil-service law which prohibit researchers from taking part in commercial activities.

Spurred on by this political pressure, the Ministry of Education, Science, Sports and

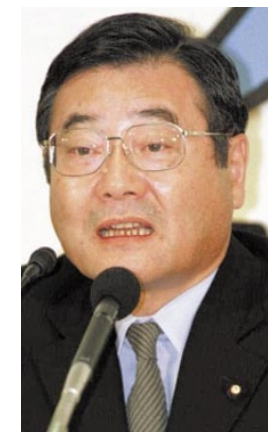

Kato: universities should be privatized.
Culture (Monbusho), which had opposed the government's reforms, has announced that it intends to approve the plan, provided that the universities are managed under a different framework from other research institutes.

Monbusho officials say the pressure to reduce the number of civil servants was now too strong for the ministry to keep resisting the plan, as national universities have more than 125,000 staff, a sizeable proportion of Japan's civil servants.

But Monbusho argues that the current agency bill, which sets targets based on cost performance, could affect the standard of research and education.

The ministry plans to ask that the bill be modified or that there should be a separate bill for universities, so their priorities would not be dictated by financial performance.
It insists that the evaluation of each agency be carried out by an independent assessment body, which Monbusho plans to set up next year (see Nature 400, 704; 1999). It wants to see performance-related targets selected by the education minister.

Monbusho's committee on university reform (see Nature 400, 703; 1999) will meet today (16 September) to finalize its proposals. Monbusho is expected to announce its final decision at a general meeting of the deans of the national universities on 20 September.

This schedule has been criticized by many as being too strongly influenced by political factors. Hirokuni Ono, head of Tokyo University's staff union, says Monbusho "shouldn't be rushing its decision because of the LDP election."

"Japan spent a long time deciding whether to privatize its railway and telecommunications sector," says Minoru Oda, former director of the Institute of Space and Astronautical Sciences and a member of the Monbusho committee. "I don't see how the government could decide the fate of the universities in such a short space of time."

Asako Saegusa 